\title{
A traumatic tale of two cities: a comparison of outcomes for adults with major trauma who present to differing trauma centres in neighbouring Canadian provinces
}

Jefferson Hayre, BSc, MD*; Colin Rouse, BSc, $\mathrm{MD}^{*}$; James French, BSc, $\mathrm{BM}^{*}{ }^{\dagger}$; Jacqueline Fraser, $\mathrm{BN}$, ENCC $^{\dagger}$; lan Watson, BSc, $\mathrm{MHSc}^{\ddagger}$; Sue Benjamin, $\mathrm{BN}^{\ddagger}$; Allison Chisholm, $\mathrm{BSc}^{\ddagger}$; George Stoica, $\mathrm{PhD}^{\S}$; Beth Sealy, BA, CHIM"; Mete Erdogan, PhD, MHI"; Robert Green, MD"; Paul Atkinson, MB, BCh, BAO, $\mathrm{MA}^{*}{ }^{\dagger}$

\section{ABSTRACT}

Objectives: While the use of formal trauma teams is widely promoted, the literature is not clear that this structure provides improved outcomes over emergency physician delivered trauma care. The goal of this investigation was to examine if a trauma team model with a formalized, specialty-based trauma team, with specific activation criteria and staff composition, performs differently than an emergency physician delivered model. Our primary outcome was survival to discharge or 30 days.

Methods: An observational registry-based study using aggregate data from both the New Brunswick and Nova Scotia trauma registries was performed with data from April 1, 2011 to March 31, 2013. Inclusion criteria included patients 16 years-old and older who had an Injury Severity Score greater than 12, who suffered a kinetic injury and arrived with signs of life to a level-1 trauma centre.

Results: 266 patients from the trauma team model and 111 from the emergency physician model were compared. No difference was found in the primary outcome of proportion of survival to discharge or 30 days between the two systems (0.88, $\mathrm{n}=266$ vs. $0.89, \mathrm{n}=111 ; \mathrm{p}=0.8608$ ).

Conclusions: We were unable to detect any difference in survival between a trauma team and an emergency physician delivered model.

\section{RÉSUMÉ}

Objectifs: Bien que la formation d'équipes structurées, spécialisées en traumatologie soit grandement préconisée, il n'est pas clair dans la documentation que ce genre de structure donne de meilleurs résultats que ceux produits par les urgentologues chargés de la prestation des soins d'urgence. L'étude avait donc pour but d'examiner si le modèle des équipes structurées en traumatologie, dotées d'un personnel particulier, divisées en spécialités et mobilisées selon certains critères avait un rendement différent du modèle des urgentologues responsables de la prise en charge. Le principal critère d'évaluation consistait en la survie au moment du congé ou au bout de 30 jours.

Méthode: Il s'agit d'une étude d'observation, fondée sur des données agrégées, provenant des registres de traumatismes du Nouveau-Brunswick et de la Nouvelle-Écosse et recueillies du $1^{\mathrm{er}}$ avril 2011 au 31 mars 2013. Les critères de sélection comprenaient des patients âgés de 16 ans et plus, qui avaient un indice de gravité des blessures supérieur à 12, qui avaient subi des lésions causées par un transfert d'énergie cinétique et qui présentaient des signes de vie à l'arrivée à un centre de traumatologie de niveau $I$.

Résultats: Ont été comparés 266 patients traités selon le modèle des équipes spécialisées en traumatologie et 111, selon le modèle des urgentologues. Aucun écart n'a été relevé entre les deux systèmes quant au principal critère d'évaluation, soit la proportion de survie au moment du congé ou au bout de 30 jours $(0,88 ; \mathrm{n}=266$ contre 0,$89 ; \mathrm{n}=111 ; p=0,8608)$.

Conclusions: L'équipe de recherche n'a constaté aucun écart quant à la survie entre le modèle des équipes spécialisées en traumatologie et celui des urgentologues.

Keywords: trauma systems, trauma teams, outcomes

\section{INTRODUCTION}

Trauma is the leading cause of death in Canadians aged 1-44. ${ }^{1}$ The World Health Organization has cited injury

From *Dalhousie Medicine New Brunswick, St. John, NB; †Department of Emergency Medicine, Dalhousie University, Saint John Regional Hospital, St. John, NB; ¥New Brunswick Trauma Program, St. John, NB; §Research Services, Horizon Health Network, Saint John, NB; $\uparrow$ Trauma Nova Scotia, Nova Scotia Department of Health and Wellness, Halifax, NS; and IIDepartment of Emergency Medicine and of Critical Care Medicine, Dalhousie University, QEll Health Sciences Centre, Halifax, NS.

Correspondence to: Paul Atkinson, Department of Emergency Medicine, Dalhousie University, Horizon Health Network, Saint John Regional Hospital, 400 University Ave, Saint John, NB E2L 4L2; Email: Paul.atkinson@ dal.ca 
as the leading cause of death and disability in persons less than 60 years of age worldwide. ${ }^{2}$ Daily, more than 10,000 Canadians experience injuries requiring medical attention, $91.9 \%$ of whom visit an emergency department (ED), $6 \%$ are hospitalized, $1.6 \%$ are left partially or fully disabled, and $0.4 \%$ die. ${ }^{3}$ This leads to an annual economic burden of 26.8 billion CAD in both direct and indirect costs. ${ }^{3}$

Inclusive trauma systems are designed to provide coordinated, preplanned, and organized injury control efforts within a defined geographic area. ${ }^{4}$ These systems have a lead agency and deliver a full spectrum of care-from emergency medical services through to rehabilitation and return to work and home. ${ }^{4}$ Additionally, these inclusive trauma systems conduct injury surveillance, reporting, and prevention programs, as well as research, training, and performance improvement. ${ }^{4}$ Numerous studies have demonstrated that the implementation of a trauma system decreases the rate of mortality both internationally ${ }^{5-11}$ and within Canada. ${ }^{12}$ The Canadian Trauma System Accreditation Guidelines include a number of criteria that trauma systems have to achieve in various domains, including the system as a whole, emergency medical services, and individual trauma centres. ${ }^{13}$

The neighbouring Atlantic Canadian provinces of Nova Scotia and New Brunswick are similar in terms of population and demographics and thus provide a natural experiment to compare differences in trauma centres. ${ }^{14}$ They have separate and independent provincial trauma systems but use different models of initial care in their level-1 trauma centre. At these trauma centres, there are various differences in how trauma care is delivered. At the level-1 trauma centre in Nova Scotia, major traumas are assessed and treated by a formal trauma team with a trauma team leader, various surgical specialists, allied health professionals, and support staff. The trauma team has predetermined activation criteria based on physiological, anatomical, mechanism, and logistical factors. ${ }^{15}$ Alternatively, initial trauma care in New Brunswick is delivered by emergency physicians, with further support provided on a service-by-service model, where the emergency physician consults specialty services, allied health professionals, and support staff as needed. These preexisting differences in models of care provided an opportunity to make comparisons between this aspect of trauma care.

The goal of our study was to compare structure, process, and outcome measures between a trauma team-based model in Halifax, Nova Scotia, and an emergency physician delivered model in Saint John, New Brunswick. For the purpose of this study, the model in Nova Scotia will be referred to as the trauma team model (TTM), while and the model in New Brunswick will be referred to as the emergency physician model (EPM). The null hypothesis was that differences in trauma care between EDM and TTM patients do not affect survival to 30 days or discharge.

\section{METHODS}

\section{Study design}

This was an observational registry-based study using aggregate data from both the New Brunswick and Nova Scotia trauma registries. These trauma registries collect a wide range of data relevant to the nature of the incident, patient demographics, patient care, and patient outcomes. Data are collected through a multilayered system in which multiple sources of data are searched for patients who meet inclusion criteria for each of the two programs. Each trauma registry performs quality checks and collects information from several sources to ensure that all major trauma cases are captured. Trauma data are entered into the registry database by a team of qualified healthcare professionals, including nurses, health records personnel, and paramedics. For this study, the data were extracted by the data custodians of each trauma program and analyzed in situ. The results of these analyses were then pooled and compared.

\section{Study permissions, ethical support and data protection}

All data processing was carried out by personnel with current host institution data protection training, using encrypted media on a dedicated secure server in the host trauma program. Horizon Health Network is the registered data custodian for the New Brunswick Trauma Registry and uses systems that are compliant with current data-protection legislation. ${ }^{16}$ Ethical approval was obtained from the Horizon Health Network Research Ethics Board in New Brunswick and the Nova Scotia Health Authority Research Ethics Board in Nova Scotia. The New Brunswick Trauma Program, Trauma Nova Scotia, Ambulance New Brunswick, and Nova Scotia Emergency Health Services approved aggregate data access. Additionally, departmental support 
was received from the Departments of Emergency Medicine at the Saint John Regional Hospital (SJRH) and the Queen Elizabeth II Health Sciences Centre (QEII HSC).

\section{Selection of participants}

Patient data were extracted from the provincial trauma registries, each of which have the same inclusion criteria. ${ }^{17,18}$ Data were extracted over a two-year period (1 April 2011 to 31 March 2013). This time period was chosen since it was the longest recent period of complete data held by both registries. We included all trauma patients aged 16 years and older with an injury severity score (ISS) $>12$ (defined by AIS-2005) who suffered a kinetic injury (defined by International Statistical Classification of Diseases and Related Health Problems, 10th Revision [ICD-10] codes V01-W64 and X85-Y09) and arrived with signs of life directly to a level-1 trauma centre either via emergency medical services or as a walk-in. Excluded were inter-facility transfers, patients who arrived at hospital with absent vital signs and no resuscitative attempt in the ED, and children (age <16), as there is a dedicated paediatric hospital in Nova Scotia, but not in New Brunswick.

\section{Setting}

New Brunswick is a province of 751,171 people, $53 \%$ of whom live in an urban area. ${ }^{1}$ The province's trauma system consists of one level-1 trauma centre, one level-2 trauma centre, six level-3 trauma centres, and 12 level-5 trauma centres. ${ }^{19}$ The SJRH is the level-1 trauma centre for the province and is located in Saint John in southern New Brunswick. The SJRH is a hybrid community and teaching hospital with approximately 445 beds and 33,000 adult visits (56,000 total visits) to the ED each year. ${ }^{20,21}$ Over the course of the study, an average of 137 patients with an ISS $>12$ were seen per year, including patients transferred in. Trauma care at the SJRH has evolved from a traditional model and is primarily delivered by emergency physicians, with additional consultant services delivered by specialty staff or residents who are called as required.

Nova Scotia has a population of 921,727 , with an urban population of $57 \% .{ }^{1}$ The trauma system in Nova Scotia is composed of two tertiary-care hospitals: the QEII HSC and the IWK Health Centre (IWK). ${ }^{17}$ The QEII HSC handles all adult emergency cases, whereas the adjacent IWK serves as the paediatric referral hospital. The QEII HSC is a university teaching hospital with 685 beds and approximately 55,000 adult visits per year to the ED. ${ }^{21}$ Over the course of the study, an average of 351 patients with an ISS $>12$ were seen per year, including patients transferred in. The QEII HSC operates a trauma team with formalized activation criteria based on physiological, anatomical, mechanism, and logistical factors. ${ }^{15}$ The team consists of the trauma team leader and resident trauma team leader, who are called for every trauma that meets the criteria, on a provincial basis. Trauma team leaders at this site are physicians from various specialties, including emergency medicine, anaesthesia, neurosurgery, orthopedics, critical care, and general surgery. This is in line with a number of other trauma centres in Canada, where a combination of surgical, emergency, and other specialties are trauma team leaders. ${ }^{22}$ Additionally, the following services are paged: radiology and senior surgical residents, as well as residents from orthopaedics, plastic surgery, neurosurgery, and anaesthesia. Allied health services include respiratory therapy, portable $\mathrm{x}$-ray technicians, computed tomography (CT) technicians, paramedics, social workers, nursing administration, ED registration clerks, and porters.

\section{Methods of measurement}

For each study participant, the following data were extracted from the registry database: trauma team activation, demographic data (age, sex); injury characteristics (injury type [blunt vs. penetrating], mechanism of injury [by ICD-10 code], ISS); arrival time to the ED; transfusion of blood products; time to CT scan; transfer to operating room; length of stay in ED to operating room; survival to 30 days or discharge; discharge disposition; number of days ventilated; length of intensive care unit (ICU) stay; and length of hospital stay.

\section{Outcome measures}

The primary outcome examined was survival to discharge or 30 days, whichever came first. Secondary outcomes included five in-hospital process indicators and four additional outcomes.

The five in-hospital process indicators that were analyzed between the two systems included: the proportion of patients who received transfusions, the time to CT, the proportion of patients with severe head 
injury who received a head CT scan within an hour, the proportion of patients transferred directly to the operating room (OR), and the time from ED to OR.

The four outcomes examined in the two systems included: discharge disposition, number of days ventilated, length of ICU stay, and length of hospital stay.

\section{Data analysis}

Case data were compared between the TTM and EPM groups in three different categories: population, process indicators, and outcomes. Within these categories, cases were stratified by their ISS into three groups: all patients, patients with an ISS of 13-24, and patients with an ISS $>24$.

Basic comparisons were performed using GraphPad QuickCalcs (Graphpad Software Inc., La Jolla, CA), and an $\alpha$ level of 0.05 was chosen. The calculations and regression analyses were done with the $\mathrm{R}$ Statistical Package (v. 3.3.2; The R Foundation for Statistical Computing, Vienna, Austria).

To be able to account for the differences between and within categories of data, we performed a multivariate mixed log-regression test with: two groups (TTM and EPM), nine independent variables (injury type, age distribution, sex, direct ED to OR, head CT in $<1$ hour with severe head injury, ISS distribution, survival, trauma team activation, transfusion), and

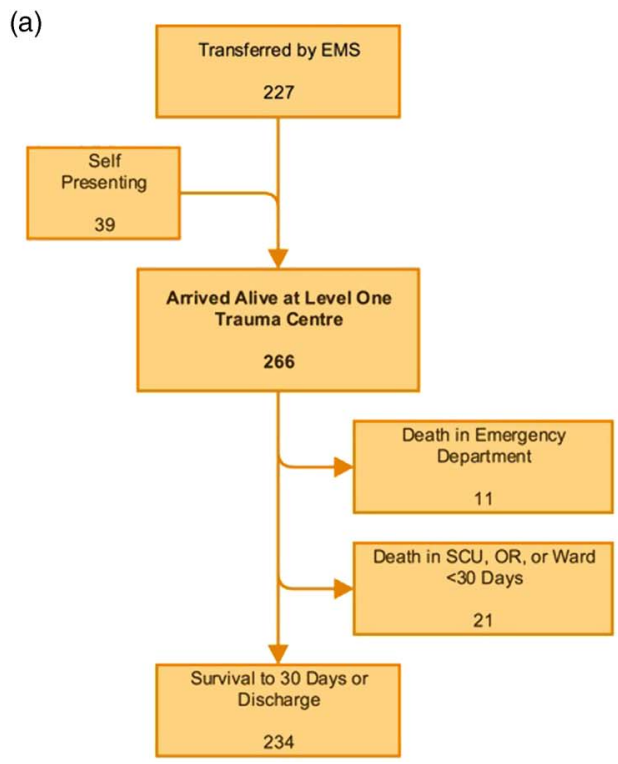

the outcome given by the differences between the TTM and EPM groups. A small effect size $\left(f^{2}=0.10\right)$ and a significant size difference of slopes fixed at 0.05 gave a power of $78 \%$ for a sample size of 266 from the TTM and 111 from the EPM groups. Continuous data were analyzed using Student's t-test. This simple parametric hypothesis testing was employed to identify significant differences between injury severity, time to CT, time from ED to OR, length of stay in hospital, length of stay in the ICU, and days ventilated.

A Fisher's exact test was utilized to compare categorical data. This simple nonparametric hypothesis test was used to identify significant differences between gender, mechanism of injury, trauma team activation, transfusions, CT in those with severe head injuries, direct transfer to the OR from the ED, survival to 30 days or discharge, as well as overall survival.

\section{RESULTS}

\section{Population}

A total of 266 cases met the inclusion criteria and arrived to hospital alive in the TTM group compared with 111 in the EPM group (Figure 1).

Population characteristics were similar, other than differences in the mechanism of injury and activation of the trauma team (Table 1). The TTM group had a

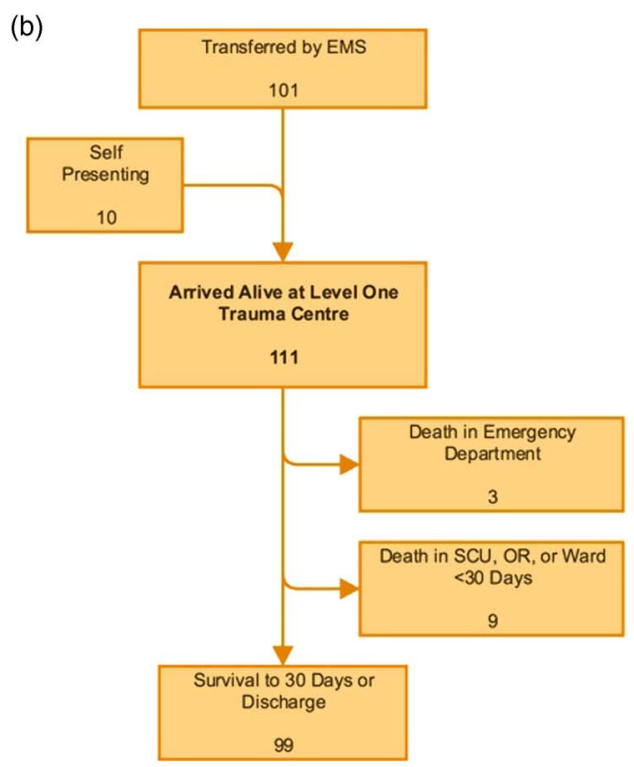

Figure 1. Population flow in the TTM and EPM groups. a) The TTM group began with 227 patients transferred by EMS and 39 who self-presented, giving 266 patients who were analyzed. b) The EPM group had 101 patient transferred by EMS and 10 who self-presented, giving a total of 111 patients who were analyzed. 


\begin{tabular}{|c|c|c|c|c|c|}
\hline Variable & & & TTM & EPM & $\mathrm{p}$ value \\
\hline \multicolumn{6}{|l|}{ Age } \\
\hline Overall & Mean \pm SD (N) & Years & $50.4 \pm 21.5(266)$ & $52.6 \pm 24.6(111)$ & 0.3864 \\
\hline Moderate injury & Mean \pm SD (N) & Years & $49.1 \pm 20.9(187)$ & $50 \pm 24.2(78)$ & 0.7609 \\
\hline Severe injury & Mean \pm SD $(\mathrm{N})$ & Years & $53.6 \pm 22.6(79)$ & $58.6 \pm 25$ & 0.3033 \\
\hline \multicolumn{6}{|l|}{ Sex } \\
\hline Overall & $\mathrm{n} / \mathrm{N}(\%)$ & Male & $189 / 266(71)$ & $80 / 111(72)$ & 0.9009 \\
\hline Moderate injury & $\mathrm{n} / \mathrm{N}(\%)$ & Male & 129/187 (69) & $56 / 78(72)$ & 0.7692 \\
\hline Severe injury & $\mathrm{n} / \mathrm{N}(\%)$ & Male & $60 / 79(76)$ & 24/33 (73) & 0.8116 \\
\hline \multicolumn{6}{|l|}{ Type of injury } \\
\hline \multirow[t]{2}{*}{ Overall } & $\mathrm{n} / \mathrm{N}(\%)$ & Blunt & 249/266 (94) & 105/111 (95) & 0.8169 \\
\hline & & Penetrating & 17/266 (6) & 6/111 (5) & \\
\hline \multirow[t]{2}{*}{ Moderate injury } & $\mathrm{n} / \mathrm{N}(\%)$ & Blunt & 175/187 (94) & 74/78 (95) & 0.7849 \\
\hline & & Penetrating & 12/187 (6) & $4 / 78(5)$ & \\
\hline \multirow[t]{2}{*}{ Severe injury } & $\mathrm{n} / \mathrm{N}(\%)$ & Blunt & 74/79 (94) & $31 / 33(94)$ & 1.000 \\
\hline & & Penetrating & $5 / 79(6)$ & 2/33 (6) & \\
\hline \multicolumn{6}{|l|}{ Mechanism of injury } \\
\hline \multirow[t]{4}{*}{ Overall } & $\mathrm{n} / \mathrm{N}(\%)$ & Transport & $119 / 266(45)$ & $35 / 111(32)$ & $0.0213^{*}$ \\
\hline & & Falls & 104/266 (39) & $57 / 111(51)$ & $0.0305^{*}$ \\
\hline & & Forces & 8/266 (3) & $8 / 111(7)$ & 0.0897 \\
\hline & & Assaults & 45/266 (13) & $11 / 111(10)$ & 0.1111 \\
\hline \multicolumn{6}{|l|}{ ISS distribution } \\
\hline Overall & Mean \pm SD (N) & & $20.4 \pm 7.1(266)$ & $19.6 \pm 5.6(111)$ & 0.2910 \\
\hline Moderate injury & Mean \pm SD (N) & & $29.2 \pm 6.1(187)$ & $27 \pm 3.6(78)$ & 0.0316 \\
\hline Severe injury & Mean \pm SD (N) & & $29.2 \pm 6.1(79)$ & $27 \pm 3.6(33)$ & 0.0558 \\
\hline \multicolumn{6}{|c|}{ Trauma team activation } \\
\hline Overall & $\mathrm{n} / \mathrm{N}(\%)$ & Activated & $134 / 266(50)$ & $0 / 111(0)$ & $<0.0001^{*}$ \\
\hline Moderate injury & $\mathrm{n} / \mathrm{N}(\%)$ & Activated & $94 / 187(50)$ & 0/78 (0) & $<0.0001^{*}$ \\
\hline Severe injury & $\mathrm{n} / \mathrm{N}(\%)$ & Activated & $40 / 79(51)$ & $0 / 33(0)$ & $<0.0001^{*}$ \\
\hline
\end{tabular}

significantly higher proportion of transport-related injuries than the EPM group $(0.45, \mathrm{n}=266$ vs. 0.32 , $\mathrm{n}=111 ; \mathrm{p}=0.0213)$. In comparison, the TTM group had a significantly smaller proportion of fall-related injuries than the EPM group $(0.39, \mathrm{n}=266$ vs. 0.51 , $\mathrm{n}=111 ; \mathrm{p}=0.0305)$. The trauma team was activated in half of all major trauma cases in the TTM group.

\section{Process indicators}

Many of the observable differences between the two systems came in the process indicator data (Table 2). Overall, there was a significant difference in the proportion of patients who received transfusions in the ED. The TTM group had a greater proportion of patients receiving transfusion of blood products than in the EPM group $(0.16, \mathrm{n}=266$ vs. $0.06, \mathrm{n}=111$; $\mathrm{p}=0.0117)$. On subgroup analysis, those patients with severe injuries also received a significantly different proportion of transfusions. Again, those in the TTM group received more transfusions than those in the EPM group $(0.28, \mathrm{n}=79$ vs. $0.06, \mathrm{n}=33 ; \mathrm{p}=0.0109)$.

Differences in mean time to CT between the TTM and EPM groups did not reach statistical significance (88.6 $\mathrm{min}, \mathrm{n}=178$ vs. $110.1 \mathrm{~min}, \mathrm{n}=85 ; \mathrm{p}=0.0946$ ). However, in subgroup analysis there was a significant difference in mean time to CT among those patients in the moderate severity group, with the TTM patients receiving CT scans faster than the EPM patients (91.9 $\min , \mathrm{n}=123$ vs. $126.4 \min , \mathrm{n}=58 ; \mathrm{p}=0.0385$ ).

The proportion of patients with a severe head injury who received a head CT within an hour of arrival to the ED was also examined. Severe head injury was defined using two criteria. First, the patient must have had an Abbreviated Injury Scale (AIS) head score $>2$. Second, the patient must have had a recorded Glasgow Coma 


\begin{tabular}{|c|c|c|c|c|c|}
\hline Variable & & & TTM & EPM & $p$ value \\
\hline \multicolumn{6}{|l|}{ Transfusion } \\
\hline Overall & $\mathrm{n} / \mathrm{N}(\%)$ & Transfused & $42 / 266(16)$ & $7 / 111(6)$ & $0.0117^{*}$ \\
\hline Moderate injury & $\mathrm{n} / \mathrm{N}(\%)$ & Transfused & 20/187 (11) & $5 / 78(6)$ & 0.3592 \\
\hline Severe injury & $\mathrm{n} / \mathrm{N}(\%)$ & Transfused & $22 / 79(28)$ & $2 / 33(6)$ & $0.0109 *$ \\
\hline \multicolumn{6}{|l|}{ Time to $\mathrm{CT}$} \\
\hline Overall & Mean $\pm S D(N)$ & Minutes & $88.6 \pm 94.7(178)$ & $110.1 \pm 102.3(85)$ & 0.0946 \\
\hline Moderate injury & Mean $\pm S D(N)$ & Minutes & $91.9 \pm 97.8(123)$ & $126.4 \pm 115.8(58)$ & $0.0385^{*}$ \\
\hline Severe injury & Mean $\pm S D(N)$ & Minutes & $81.2 \pm 87.8(55)$ & $75 \pm 50(27)$ & 0.7346 \\
\hline \multicolumn{6}{|c|}{ Head CT in patients with severe head injury } \\
\hline Overall & $\mathrm{n} / \mathrm{N}(\%)$ & CT $<1$ hour & 28/35 (80) & $11 / 22(50)$ & $0.0226^{*}$ \\
\hline Moderate injury & $\mathrm{n} / \mathrm{N}(\%)$ & CT $<1$ hour & $11 / 14(79)$ & $4 / 8(50)$ & 0.6244 \\
\hline Severe injury & $\mathrm{n} / \mathrm{N}(\%)$ & CT $<1$ hour & $17 / 21(80)$ & $7 / 14(50)$ & 0.0725 \\
\hline \multicolumn{6}{|c|}{ Direct ED to OR transfers } \\
\hline Overall & $\mathrm{n} / \mathrm{N}(\%)$ & & $72 / 266(27)$ & $12 / 111(11)$ & $0.0004^{*}$ \\
\hline Moderate injury & $\mathrm{n} / \mathrm{N}(\%)$ & & 43/187 (23) & $5 / 78(6)$ & $0.0009^{*}$ \\
\hline Severe injury & $\mathrm{n} / \mathrm{N}(\%)$ & & 29/79 (37) & $7 / 33(21)$ & 0.1254 \\
\hline \multicolumn{6}{|c|}{ Length of ED Stay to OR } \\
\hline Overall & Mean $\pm S D(N)$ & Minutes & $252.9 \pm 226.2(39)$ & $250.5 \pm 234.1(12)$ & 0.9747 \\
\hline Moderate injury & Mean $\pm S D(N)$ & Minutes & $224.3 \pm 223.7(21)$ & $370.8 \pm 304.1$ (5) & 0.2299 \\
\hline Severe injury & Mean $\pm S D(N)$ & Minutes & $286.4 \pm 230.8(18)$ & $164.4 \pm 134.7(7)$ & 0.2051 \\
\hline
\end{tabular}

Scale (GCS) score $<9$ on the scene or upon arrival to $\mathrm{ED}$, or have been intubated or ventilated on the scene or on arrival to the ED. In this group of severely headinjured patients, a greater proportion received a head CT within an hour in the TTM compared to the EPM group (0.80, $\mathrm{n}=35$ vs. $0.50, \mathrm{n}=22 ; \mathrm{p}=0.0226)$.

Patient transfers to the OR from the ED were also analyzed for both the proportion of direct transfers and time to OR. Overall, TTM patients went to the OR directly more often than EPM patients $(0.27, \mathrm{n}=266$ vs. $0.11, \mathrm{n}=111 ; \mathrm{p}=0.0004)$. Patients in the moderate severity group also went directly to the OR more often in the TTM than in the EPM group $(0.23, \mathrm{n}=187$ vs. 0.06 , $\mathrm{n}=78 ; \mathrm{p}=0.0009)$. There was no difference for severely injured patients $(0.37, \mathrm{n}=79$ vs. $0.21, \mathrm{n}=33$; $\mathrm{p}=0.1254)$. However, for patients who did go directly to the OR from the ED, there was no statistically significant difference in terms of process time.

\section{Primary outcomes}

When examining the primary outcome (Table 3), there was no difference in the proportion of patients who survived to discharge or 30 days between the TTM and EPM groups $(0.88, \mathrm{n}=266$ vs. $0.89, \mathrm{n}=111$; $\mathrm{p}=0.8608$ ) (Figure 2). There were no differences between the TTM and EPM groups in the proportion of patients discharged home $(0.72, \mathrm{n}=230$ vs. $0.76, \mathrm{n}=95 ; \mathrm{p}=0.4948$ ), or mean time spent in the hospital (23.5 days, $\mathrm{n}=249$ vs. 16.9 days, $\mathrm{n}=108$; $\mathrm{p}=0.2703)$, ICU length of stay (6.7 days, $\mathrm{n}=74$ vs. 6.3 days, $\mathrm{n}=61 ; \mathrm{p}=0.7184$ ), or time ventilated (5.2 days, $\mathrm{n}=65$ vs. 4.1 days, $\mathrm{n}=29 ; \mathrm{p}=0.3587$ ).

A regression was performed on statistically significant data (direct ED to OR, head CT in $<1$ hour with severe head injury, trauma team activation, and transfusion), aggregated, and normalized. The dependent variable (outcomes) showed statistically nonsignificant differences between the TTM and the EPM groups, a finding supported by the previously presented output of the multivariate mixed log-regression test.

\section{DISCUSSION}

The goal of this study was to determine if there was a difference in outcomes between a model of trauma care with a formalized trauma team having set activation criteria and a trauma model with emergency physiciandelivered care. The study was powered at $78 \%$ and did not disprove the null hypothesis, and no differences 


\begin{tabular}{|c|c|c|c|c|c|}
\hline Variable & & & TTM & EPM & $p$ value \\
\hline \multicolumn{6}{|c|}{ Survival to discharge or 30 days } \\
\hline Overall & $\mathrm{n} / \mathrm{N}(\%)$ & & $234 / 266(88)$ & 99/111 (89) & 0.8608 \\
\hline Moderate injury & $\mathrm{n} / \mathrm{N}(\%)$ & & 178/187 (95) & 77/78 (99) & 0.2896 \\
\hline Severe injury & $\mathrm{n} / \mathrm{N}(\%)$ & & $56 / 79(71)$ & $22 / 33(66)$ & 0.6589 \\
\hline \multicolumn{6}{|c|}{ Discharge disposition } \\
\hline Overall & $\mathrm{n} / \mathrm{N}(\%)$ & Home & $165 / 230(72)$ & $72 / 95(76)$ & 0.4948 \\
\hline Moderate injury & $\mathrm{n} / \mathrm{N}(\%)$ & Home & 136/175 (78) & $63 / 75(84)$ & 0.3061 \\
\hline Severe injury & $\mathrm{n} / \mathrm{N}(\%)$ & Home & 29/55 (53) & $9 / 20(45)$ & 0.6086 \\
\hline \multicolumn{6}{|c|}{ Length of hospital stay } \\
\hline Overall & Mean \pm SD (N) & Days & $23.5 \pm 59.2(249)$ & $16.9 \pm 28.4(108)$ & 0.2703 \\
\hline Moderate injury & Mean \pm SD (N) & Days & $17.2 \pm 31(178)$ & $17.1 \pm 31.9(77)$ & 0.9813 \\
\hline Severe injury & Mean \pm SD (N) & Days & $39.2 \pm 98.1(71)$ & $16.5 \pm 17.4(31)$ & 0.2049 \\
\hline \multicolumn{6}{|l|}{ Length of ICU stay } \\
\hline Overall & Mean \pm SD (N) & Days & $6.7 \pm 6.4(74)$ & $6.3 \pm 6.4(61)$ & 0.7184 \\
\hline Moderate injury & Mean \pm SD (N) & Days & $6.8 \pm 7.4(36)$ & $4.5 \pm 3.3(35)$ & 0.0969 \\
\hline Severe injury & Mean \pm SD $(N)$ & Days & $6.7 \pm 5.4(38)$ & $8.8 \pm 8.5(26)$ & 0.2310 \\
\hline \multicolumn{6}{|l|}{ Length of ventilation } \\
\hline Overall & Mean $\pm S D(N)$ & Days & $5.2 \pm 5.8(65)$ & $4.1 \pm 4.1(29)$ & 0.3587 \\
\hline Moderate injury & Mean $\pm S D(N)$ & Days & $5.7 \pm 6.9(30)$ & $3.6 \pm 3.6(11)$ & 0.3443 \\
\hline Severe injury & Mean $\pm S D(N)$ & Days & $4.7 \pm 4.7(35)$ & $4.3 \pm 4.4(18)$ & 0.7657 \\
\hline
\end{tabular}

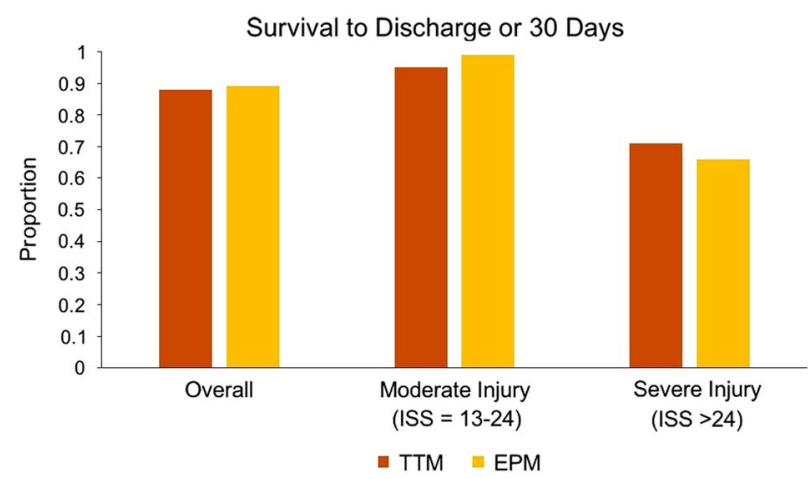

Figure 2. Survival to discharge or 30 days. There was no difference in the proportion of patients who survived to discharge or 30 days between the TTM and the EPM groups (0.88, $\mathrm{n}=266$ vs. $0.89, \mathrm{n}=111 ; \mathrm{p}=0.8608$ ).

between the TTM and EPM groups were observed for any of the primary outcome measures, including survival to 30 days, or for the secondary outcomes of discharge disposition, length of hospital or ICU stay, or duration of ventilation.

Published reports regarding the clinical effectiveness of differently composed trauma teams have revealed varying results. A study by Khetarpal et al. ${ }^{23}$ in 1999 found that the presence of a trauma surgeon on the trauma team decreased resuscitation time and time to incision, but this had no effect on mortality. A study by Durham et al. ${ }^{24}$ in 2005 showed that implementation of in-house call of a trauma surgeon attending present for resuscitation showed no change in length of hospital stay, length of stay in the ICU, days ventilated, or overall mortality; however, it did show a decrease in preventable deaths. A review by Green et al. ${ }^{25}$ in 2006 determined that there was a lack of evidence to support the premise that trauma outcomes improve with the routine presence of a trauma surgeon on patient arrival. A 2005 study by Ahmed et al. ${ }^{26}$ demonstrated no difference in outcome between patients with surgical trauma leads or nonsurgical trauma leads. However, a study by Petrie et al. ${ }^{27}$ in 1996 showed that activation of the trauma team led to improved outcomes of trauma patients compared to when the trauma team was not activated.

Despite the lack of difference in outcomes, there were several differences between the systems for certain process indicators, either overall or in subgroup analysis. These differences all favoured the TTM, with a greater proportion of patients receiving transfusions, shorter times to completing full-body CT, a greater proportion of those with head injuries receiving head 
CT within an hour, and a greater proportion of patients transferred directly to the OR. As noted, despite the favourable performance of the TTM for these process indicators, there were no observable differences in patient outcomes.

Overall, our regional interprovincial findings confirm the conclusions of previously published studies which have reported that, although formal specialty-based trauma team systems may improve such markers of care as time to investigation or time to operative intervention, these systemic differences may not equate to improvements in patient outcome. ${ }^{23-25,28}$ The published literature, in line with our study, suggests that there are measurable benefits with expert-based trauma care, but it does not differentiate between emergency physician- and specialty-based trauma team models. What is clearly important is that patients receive quality care in a timely manner.

\section{LIMITATIONS}

There are a number of limitations to this study. Aggregate data were analyzed, as case-level data could not be shared between jurisdictions due to privacy restrictions. Although we found minimal differences in population characteristics, this restricted our ability to account for such potential confounding variables as age, ISS, and type and mechanism of injury. In addition to patient differences, we were unable to account for differences in training or seniority among clinicians. It is possible that any beneficial effect that TTMs may have over EPMs, or vice versa, could be eliminated or exaggerated if either system had varying proportions of junior training grade or senior staff physicians. It is also important to note that the secondary outcomes of lengths of stay included patients who died while in the ICU or while ventilated, and this may have skewed the data. However, this was the only form in which these data could be collected from both trauma registries. Given that this was the first study of its kind to share data between the two registries, using aggregate data was a more achievable first step.

\section{CONCLUSION}

Although we were able to demonstrate differences in processes of trauma care delivery between trauma team and emergency physician models in neighbouring trauma systems, we were unable to detect any differences in survival or disposition outcomes. Further analysis of case-level data is required to confirm whether or not our finding of no outcome difference is accurate.

Competing interests: None to declare.

\section{REFERENCES}

1. Statistics Canada. 2011 Census of Population Program. Ottawa: Statistics Canada; 2011. Available at: http://www 12.statcan.gc.ca/census-recensement/2011/dp-pd/index-eng. $\mathrm{cfm}$.

2. Peden M, McGee K, Krug E. Injury: A Leading Cause of the Global Burden of Disease, 2000. Geneva: World Health Organization; 2000. Available at: http://www.who.int/vio lence_injury_prevention/publications/other_injury/injury/en/.

3. Ontario Injury Prevention Resource Centre. Cost of Injury in Canada (2015). Toronto: Ontario Injury Prevention Resource Centre; 2015. Available at: http://www.onin juryresources.ca/publications/item/cost-of-injury-in-canada2015.

4. Trauma Association of Canada. Trauma System Accreditation Guidelines. Toronto: Trauma Association of Canada; 2011. Available at: http://www.traumacanada.ca/accredita tion_committee/Accreditation_Guidelines_2011.pdf.

5. Cayten CG, Quervalu I, Agarwal N. Fatality analysis reporting system demonstrates association between trauma system initiatives and decreasing death rates. 7 Trauma 1999;46(5):751-6.

6. Celso B, Tepas J, Langland-Orban B, et al. A systematic review and meta-analysis comparing outcome of severely injured patients treated in trauma centers following the establishment of trauma systems. 7 Trauma 2006;60(2):371-8.

7. Cornwell EE III, Chang DC, Phillips J, Campbell KA. Enhanced trauma program commitment at a level I trauma center. Arch Surg 2003;138(8):838-43.

8. MacKenzie EJ, Rivara FP, Jurkovich GJ, et al. A national evaluation of the effect of trauma-center care on mortality. N Engl 7 Med 2006;354(4):366-78.

9. Nathens AB, Jurkovich GJ, Cummings P, Rivara FP, Maier $\mathrm{RV}$. The effect of organized systems of trauma care on motor vehicle crash mortality. 7 Am Med Assoc 2000; 283(15):1990-4.

10. Nathens AB, Jurkovich GJ, Rivara FP, Maier RV. Effectiveness of state trauma systems in reducing injury-related mortality: a national evaluation. 7 Trauma 2000;48(1):25-31.

11. Utter GH, Maier R V, Rivara FP, et al. Inclusive trauma systems: do they improve triage or outcomes of the severely injured? 7 Trauma 2006;60(3):529-37.

12. Mckee JL, Roberts DJ, van Wijngaareden-Stephens MH, et al. The right treatment at the right time in the right place: a population-based, before-and-after study of outcomes associated with implementation of an all-inclusive trauma system in a large Canadian province. Ann Surg 2014;261(3): 558-64. 
13. Accreditation Canada. Trauma Distinction Information Package. Ottawa: Accreditation Canada; 2014. Available at: https://accreditation.ca/sites/default/files/trauma-info-pack age-en.pdf.

14. Statistics Canada. Annual Demographic Estimates: Canada, Provinces and Territories. (91-215-X). Ottawa: Statistics Canada; 2012. Available at: http://www5.statcan.gc.ca/olc-cel/ olc.action?objId=91-215-X\&obj Type=2\&lang=en\&limit $=0$.

15. Nova Scotia Trauma. QEII HSC Trauma Team Activation Criteria. Halifax: Emergency Health Services; 2011. Available at: http://www.docs-engine.com/pdf/1/traumateam.html.

16. New Brunswick Attorney General. The Personal Health Information Privacy and Access Act. Fredericton: New Brunswick Attorney General; 2016. Available at: http:// www2.gnb.ca/content/dam/gnb/Departments/h-s/pdf/en/ HealthActs/Custodian_Facts.pdf.

17. Nova Scotia Trauma Program. Trauma Registry Report of Injury in Nova Scotia. Halifax: Nova Scotia Trauma Program; 2014-15. Available at: http://www.trauma-ns.com/ 2015-annual-report.

18. New Brunswick Trauma. Trauma Registry. St. John: New Brunswick Trauma; 2016. Available at: http://devwebs.zedit solutions.com/home/facilities-and-services/provincial-programs/ new-brunswick-trauma-program/health-care-professionals/ program-resources/trauma-registry.aspx.

19. New Brunswick Trauma Program. New Brunswick Trauma Program Annual Report, 2014. St. John: New Brunswick Trauma Program; 2014. Available at: http://devwebs.zedit solutions.com/media/644590/annual_report_2014_final.pdf.
20. Horizon Health Network. Saint John Regional Hospital. St. John: Horizon Health Network; 2015. Available at: http://en.horizonnb.ca/home/facilities-and-services/facilities/ saint-john-regional-hospital.aspx.

21. Dalhousie University. Department of Emergency Medicine. Halifax: Dalhousie University Faculty of Medicine; 2017. Available at: http://medicine.dal.ca/departments/depart ment-sites/emergency/about/facilities.html.

22. Lavoie A, Tsaknoas E, Sampalis J, Fréchette P. Medical specialties assuming the role of trauma team leader in Canadian trauma centres. Eur 7 Trauma 2003;29:145-50.

23. Khetarpal S, Steinbrunn B, McGonigal M, et al. Trauma faculty and trauma team activation: impact on trauma system function and patient outcome. 7 Trauma 1999;47(3): 576-81.

24. Durham R, Shapiro D, Flint L. In-house trauma attendings: is there a difference? Am 7 Surg 2005;190(6):984-90.

25. Green SM. Is there evidence to support the need for routine surgeon presence on trauma patient arrival? Ann Emerg Med 2006;47(5):405-11.

26. Ahmed JM, Tallon JM, Petrie DA. Trauma management outcomes associated with nonsurgeon versus surgeon trauma team leaders. Ann Emerg Med 2005;50(1):7-13.

27. Petrie D, Lane P, Stewart TC. An evaluation of patient outcomes comparing trauma team activated versus trauma team not activated using TRISS analysis. 7 Trauma 1996; 41(5):870-5.

28. Hameed SM, Schuurman N, Razek T, et al. Access to trauma systems in Canada. 7 Trauma 2010;69(6):1350-61. 